\title{
Digestibilidade de dietas suplementadas com fitase para suínos sob diferentes ambientes térmicos
}

\author{
Digestibility of diets supplemented with phytase for pigs under different thermal environments
}

\author{
Charles Kiefer ${ }^{I *}$ Tânia Mara Baptista dos Santos ${ }^{\mathrm{II}}$ Mariana de Souza Moura ${ }^{\mathrm{I}}$ \\ Camilla Mendonça Silva ${ }^{I}$ Lúcia dos Santos Lucas ${ }^{I}$ Elaine Mariza Rosa ${ }^{I}$
}

\section{RESUMO}

Realizou-se um ensaio de digestibilidade com o objetivo de avaliar níveis de fitase sobre a digestibilidade e excreção de nutrientes para suínos submetidos a condições de conforto e estresse térmico. Foram utilizados 24 suínos machos castrados, alojados em gaiolas metabólicas, em câmara climatizada, distribuídos em delineamento de blocos ao acaso em esquema fatorial $2 \times 4$, com dois ambientes $\left(23\right.$ e $\left.31^{\circ} \mathrm{C}\right)$ e quatro níveis de fitase $\left(0,300,600\right.$ e $900 U \mathrm{~F} \mathrm{~kg}^{-1}$ de ração), com três repetições, sendo cada unidade experimental constituída por um animal. Concluiu-se que as dietas fornecidas aos suínos submetidos ao estresse térmico $\left(31^{\circ} \mathrm{C}\right)$ apresentam menores coeficientes de digestibilidade da proteína, fósforo, cálcio, zinco, ferro e magnésio e, portanto, apresentam maior excreção percentual desses nutrientes nas fezes, quando comparadas às dietas fornecidas aos suínos submetidos à termoneutralidade $\left(23^{\circ} \mathrm{C}\right)$. A suplementação de fitase não altera o valor energético da dieta e o coeficiente de digestibilidade da proteína, mas aumenta o coeficiente de digestibilidade de fósforo, cálcio e magnésio e reduz a excreção percentual de fósforo e cálcio nas fezes dos suínos. Recomenda-se o nível de inclusão de $300 U F \mathrm{~kg}^{-1}$ de ração, independentemente da condição térmica ambiental.

Palavras-chave: Aspergillus níger, dejetos, digestibilidade, enzima, impacto ambiental.

\section{ABSTRACT}

We conducted a digestibility trial with the aim of evaluate phytase levels on digestibility and nutrient excretion for pigs submitted to thermoneutral conditions and heat stress. We used 24 barrows housed in metabolic cages in climatic chamber, distributed in randomized blocks in a $2 \times 4$ factorial design, two environments $\left(23\right.$ and $31^{\circ} \mathrm{C}$ ) and four phytase levels (0,300, 600 and 900UF $\mathrm{kg}^{-1}$ diet), with three replicates and each experimental unit consists of one animal. It was concluded that pigs submitted to high ambient temperatures $\left(31^{\circ} \mathrm{C}\right)$ have worse digestibility of protein, phosphorus, calcium, zinc, iron and magnesium and therefore have a higher percentage of nutrients excreted in feces when compared to pigs submitted to thermoneutral environment $\left(23^{\circ} \mathrm{C}\right)$. Phytase supplementation did not alter the energy value of feed and the digestibility coefficient of protein, but it increases the digestibility coefficient of phosphorus, calcium and magnesium and reduces the percentage of phosphorus and calcium in the faeces of pigs. We recommend the inclusion level of $300 \mathrm{UF} \mathrm{kg}^{-1}$ feed, regardless of the environmental thermal condition.

Key words: Aspergillus níger, waste, digestibility, enzyme, environmental impact.

\section{INTRODUÇÃO}

As dietas tradicionais dos suínos no Brasil são constituídas basicamente por milho e farelo de soja. Esses ingredientes possuem aproximadamente dois terços do fósforo na forma de fitato, cuja disponibilidade é baixa para os monogástricos (ADEOLA \& SANDS, 2003). Nesse sentido, a fitase exógena tem sido empregada com objetivo de aumentar a disponibilidade de fósforo e outros minerais (JENDZA et al., 2005). Além disso, dependendo do preço dos ingredientes, a fitase pode reduzir o custo das dietas, uma vez que possibilita a redução da inclusão de fósforo inorgânico.

'Universidade Federal de Mato Grosso do Sul (UFMS), 79074-460, Campo Grande, MS, Brasil. E-mail: charles.kiefer@ufms.br.

*Autor para correspondência.

"Universidade Estadual de Mato Grosso do Sul (UEMS), Aquidauana, MS, Brasil. 
Além do fitato, existem os fatores ambientais que também podem afetar os suínos. Sabe-se que animais submetidos a temperaturas ambientais efetivas acima da zona de conforto térmico apresentam mecanismos comportamentais, físicos e químicos para redução das taxas metabólicas e, consequentemente, da produção de calor. A redução da concentração dos hormônios tireoidanos no soro (OLIVEIRA \& DONZELE, 1999), redução da atividade metabólica de órgãos como o fígado, rins e intestinos (GUERNSEY \& STEVENS, 1977), que são os responsáveis por grande parte da produção de calor corporal e o aumento da frequência respiratória, podem ocasionar desvios de nutrientes, reduzindo a taxa e a eficiência de sua utilização para o crescimento (KIEFER et al., 2009).

Portanto, é necessário ampliar os conhecimentos quanto à utilização da fitase, relacionando as questões nutricionais e suas interações com o ambiente térmico. Realizou-se este trabalho com o objetivo de avaliar níveis de fitase sobre a digestibilidade e excreção de nutrientes em dietas formuladas a base de milho e farelo de soja para suínos submetidos a condições de termoneutralidade $\left(23^{\circ} \mathrm{C}\right) \mathrm{e}$ de estresse térmico $\left(31^{\circ} \mathrm{C}\right)$.

\section{MATERIAL E MÉTODOS}

O ensaio de digestibilidade foi realizado na Faculdade de Medicina Veterinária e Zootecnia da Universidade Federal de Mato Grosso do Sul, em Campo Grande/MS. Foram utilizados 24 suínos, machos castrados de mesmo padrão genético, alojados em câmara climatizada equipada com gaiolas metabólicas, tendo 12 animais sido alojados sob ambiente de termoneutralidade $\left(23^{\circ} \mathrm{C}\right)$, com peso inicial de $44,9 \pm 7,1 \mathrm{~kg}$ e 12 animais sob ambiente de estresse por calor $\left(31^{\circ} \mathrm{C}\right)$, com peso inicial de $50,4 \pm 1,3 \mathrm{~kg}$.

Os animais foram distribuídos em delineamento de blocos ao acaso em esquema fatorial $2 \times 4$, constituído por dois ambientes térmicos $\left(23^{\circ} \mathrm{C}\right.$ e $\left.31^{\circ} \mathrm{C}\right)$ e quatro níveis de fitase $\left(0,300,600\right.$ e $900 \mathrm{UF} \mathrm{kg}^{-1}$ de ração), com três repetições, sendo cada unidade experimental constituída por um animal. Na formação dos blocos, levou-se em consideração o peso inicial dos animais para cada ambiente térmico avaliado.

Durante o período experimental, a temperatura e a umidade relativa da sala foram monitoras diariamente, por meio de termômetros de bulbo seco e úmido e de globo negro. Os valores registrados foram convertidos no índice de temperatura de globo e umidade (ITGU), para caracterizar o ambiente térmico em que os animais foram mantidos. $\mathrm{O}$ ensaio de digestibilidade teve duração de 12 dias, sendo sete dias para a adaptação dos animais às gaiolas, ao ambiente e às dietas experimentais e cinco dias para as coletas de fezes e urina.

As dietas experimentais (Tabela 1) foram preparadas a base de milho e farelo de soja, suplementadas com vitaminas, aminoácidos e minerais, exceto fósforo, sendo formuladas de acordo com ROSTAGNO et al. (2005). Os diferentes níveis de fitase foram obtidos pela inclusão de fitase exógena (mínimo de 10.000UF g ${ }^{-1}$ de produto) em substituição ao caulim. A quantidade de ração fornecida diariamente a cada animal foi calculada com base no consumo durante o período de adaptação e no peso metabólico $\left(\mathrm{PM}^{0,75}\right)$, sendo mantido constante durante o período experimental. A quantidade de ração calculada para o consumo diário foi subdividida em duas refeições diárias (8 e 16 horas), sendo oferecida úmida para evitar desperdícios e facilitar a ingestão. Aágua foi fornecida à vontade aos animais.

Foi adotada a metodologia de coleta total das fezes. Para definir o início e o término do período de coleta foram adicionados $2 \%$ de óxido férrico $\left(\mathrm{Fe}_{2} \mathrm{O}_{3}\right)$ às dietas como marcador indigerível. As fezes foram coletadas diariamente às $8 \mathrm{~h} 30 \mathrm{~min}$ e $16 \mathrm{~h} 30 \mathrm{~min}$, foram pesadas, acondicionadas em sacos plásticos identificados e armazenadas em freezer. Ao término do experimento, as fezes foram descongeladas, homogeneizadas e retirou-se uma amostra de aproximadamente $300 \mathrm{~g}$ para a realização das análises laboratoriais. A urina excretada foi drenada em baldes plásticos equipados com filtro e contendo $20 \mathrm{ml}$ de $\mathrm{HCl}$ (1:1) para evitar a proliferação bacteriana e perdas de nitrogênio. A coleta foi realizada diariamente visando mensurar o volume produzido. Posteriormente, coletouse $10 \%$ do volume total produzido por animal para ser armazenada em freezer para a realização das análises laboratoriais.

As determinações da matéria seca, cinzas, fósforo e proteína das dietas, fezes e urina foram realizadas de acordo com metodologia descrita por SILVA \& QUEIROZ (2002). A energia bruta (EB) das dietas, fezes e urina foram determinadas utilizando a bomba calorimétrica e os teores de cálcio, ferro, zinco e magnésio foram determinados por meio de espectrofotometria de absorção atômica, de acordo com AOAC (1984). A partir das concentrações de EB das dietas, fezes e urina, foram determinadas a energia digestível (ED) e metabolizável (EM) das dietas experimentais. Os coeficientes de digestibilidade dos nutrientes foram calculados conforme SAKOMURA \& ROSTAGNO (2007). Os minerais da água foram desconsiderados, devido às concentrações insignificantes. 
Tabela 1 - Composição centesimal e nutricional das dietas experimentais.

\begin{tabular}{|c|c|c|c|c|}
\hline \multirow{2}{*}{ Ingredientes } & \multicolumn{4}{|c|}{----Fitase (UF kg-1 de ração) -- } \\
\hline & 0 & 300 & 600 & 900 \\
\hline Milho & 74,691 & 74,691 & 74,691 & 74,691 \\
\hline Farelo de soja ( $45 \%)$ & 22,762 & 22,762 & 22,762 & 22,762 \\
\hline Calcário & 1,234 & 1,234 & 1,234 & 1,234 \\
\hline Mistura mineral $^{1}$ & 0,050 & 0,050 & 0,050 & 0,050 \\
\hline Mistura vitamínica $^{2}$ & 0,400 & 0,400 & 0,400 & 0,400 \\
\hline Sal comum & 0,321 & 0,321 & 0,321 & 0,321 \\
\hline L-Lisina $\mathrm{HCl}$ & 0,304 & 0,304 & 0,304 & 0,304 \\
\hline L-Treonina & 0,078 & 0,078 & 0,078 & 0,078 \\
\hline DL-Metionina & 0,070 & 0,070 & 0,070 & 0,070 \\
\hline Fitase & 0,000 & 0,030 & 0,060 & 0,090 \\
\hline Caulim & 0,090 & 0,060 & 0,030 & 0,000 \\
\hline Total & 100,00 & 100,00 & 100,00 & 100,00 \\
\hline -------------------' & ----Comp & nal calcu & & \\
\hline Proteína bruta $(\%)$ & 16,85 & 16,85 & 16,85 & 16,85 \\
\hline Energia metabolizável $\left(\mathrm{kcal} \mathrm{kg}^{-1}\right)$ & 3.230 & 3.230 & 3.230 & 3.230 \\
\hline Lisina total $(\%)$ & 1,077 & 1,077 & 1,077 & 1,077 \\
\hline Lisina digestível (\%) & 0,953 & 0,953 & 0,953 & 0,953 \\
\hline Treonina digestível (\%) & 0,621 & 0,621 & 0,621 & 0,621 \\
\hline Met+Cist digestível (\%) & 0,572 & 0,572 & 0,572 & 0,572 \\
\hline Triptofano digestível (\%) & 0,170 & 0,170 & 0,170 & 0,170 \\
\hline Cálcio (\%) & 0,551 & 0,551 & 0,551 & 0,551 \\
\hline Fósforo disponível (\%) & 0,100 & 0,100 & 0,100 & 0,100 \\
\hline Fósforo total (\%) & 0,300 & 0,300 & 0,300 & 0,300 \\
\hline Sódio (\%) & 0,170 & 0,170 & 0,170 & 0,170 \\
\hline
\end{tabular}

${ }^{1}$ Conteúdo por quilograma de produto: ferro, $100 \mathrm{~g}$; cobre, $10 \mathrm{~g}$; cobalto, 0,2g; manganês, 30g; zinco, 100g; iodo, 1,0g; selênio, 0,3g e excipiente q.s.p., $1000 \mathrm{~g}$.

${ }^{2}$ Conteúdo por quilograma de produto: Vit. A, 6.000.000UI; Vit. D 3 , 1.000.000UI; Vit. E, 12.000UI; Vit. B 1 , 0,5g; Vit. B , 2,6g; Vit. B $0,7 \mathrm{~g}$; ácido pantotênico, $10 \mathrm{~g}$; Vit. $\mathrm{K}_{3}, 1,5 \mathrm{~g}$; ácido nicotínico, 22g; Vit. B12, 0,015g; ácido fólico, 0,2g; biotina, 0,05g; colina, 100g e excipiente q.s.p., $1000 \mathrm{~g}$.

* Composição nutricional calculada de acordo com ROSTAGNO et al. (2005)

Os dados obtidos foram submetidos à análise de variância pelo procedimento GLM. Adotouse o modelo estatístico representado por: $\mathrm{y}_{\mathrm{jik}}=\mu+\mathrm{b}_{\mathrm{j}}+\mathrm{f}_{\mathrm{i}}+\mathrm{a}_{\mathrm{k}}+\mathrm{p}_{\mathrm{fik}}+\mathrm{e}_{\mathrm{jik}}$; em que $\mathrm{y}_{\mathrm{jik}}$ é o valor observado da variável resposta que pertence à gaiola jik; $\mu=$ estimativa da média geral; $b_{j}=$ efeito do bloco $j ; f_{i}=$ efeito do nível de fitase $\mathrm{i} ; \mathrm{a}_{\mathrm{k}}=$ efeito do ambiente térmico $\mathrm{k} ; \mathrm{fa}_{\mathrm{ik}}=$ efeito da interação entre o nível de fitase i e o ambiente térmico $\mathrm{k}$; $\mathrm{e}_{\mathrm{jik}}=$ erro experimental. Realizou-se o desdobramento da interação fitase $\mathrm{x}$ ambiente, avaliando-se os níveis de fitase dentro de cada ambiente térmico. $\mathrm{O}$ efeito dos níveis de fitase foi desdobrado em componentes linear, quadrático ou modelo descontínuo linear response plateau. As diferenças entre médias para o fator ambiente foram comparadas pelo Teste F. As análises foram realizadas por intermédio de programa estatístico, em nível de $10 \%$ de significância.

\section{RESULTADOS E DISCUSSÃO}

No ambiente de conforto térmico, a temperatura do ar da sala foi $23,4 \pm 1,2^{\circ} \mathrm{C}$, a umidade relativa foi $87,6 \pm 8,4 \%$, a temperatura de globo negro foi $23,9 \pm 0,9^{\circ} \mathrm{C}$ e o ITGU de $72,9 \pm 1,1$. A temperatura média do ar registrada nesse ambiente pode ser considerada como de termoneutralidade por estar entre $18 \mathrm{a} 26^{\circ} \mathrm{C}$, que é a faixa de temperaturas proposta como ideal para essa categoria (PERDOMO, 1994). Por sua vez, no ambiente de estresse por calor, a temperatura do ar da sala foi $30,4 \pm 2,3^{\circ} \mathrm{C}$, a umidade relativa foi $76,0 \pm 9,4 \%$, a temperatura de globo negro foi $31,6 \pm 1,4^{\circ} \mathrm{C}$ e o ITGU calculado foi $81,9 \pm 1,7$. A temperatura média do ar registrada neste tratamento pode ser considerada como de estresse por calor, por estar acima da temperatura crítica máxima de $27^{\circ} \mathrm{C}$ estabelecida para a categoria (SAMPAIO et al., 2004). 
Não houve interação $(\mathrm{P}>0,10)$ entre os níveis de fitase e o ambiente térmico sobre a excreção de nutrientes (Tabela 2). Suínos submetidos ao ambiente com temperaturas elevadas $\left(31^{\circ} \mathrm{C}\right)$ apresentaram maior excreção percentual de proteína bruta $(\mathrm{P}<0,07)$, fósforo e cálcio $(P<0,01)$, zinco e magnésio $(P<0,03)$ nas fezes. Por outro lado, a excreção de ferro não foi influenciada $(\mathrm{P}>0,10)$ pelo ambiente térmico. A temperatura do ar é um dos fatores de maior influência sobre o comportamento, fisiologia e metabolismo dos suínos, uma vez que eles possuem baixa capacidade de perda de calor em situações de temperaturas ambientais elevadas (HUYNH et al., 2005). Nessas condições, ocorre a redução dos níveis de hormônios T3 e T4 circulantes (OLIVEIRA \& DONZELE, 1999), o que leva à redução da atividade da bomba de sódio $\left(\mathrm{Na}^{+}, \mathrm{K}^{+} \mathrm{e}\right.$ ATPase) e à redução da atividade metabólica do fígado, rins e intestinos, visando a minimizar a produção de calor corporal (GUERNSEY \& STEVENS, 1977). A redução do peso do fígado, intestinos, pâncreas e rins está diretamente correlacionada à redução da produção de calor corporal (KOONG et al., 1982), fato que, provavelmente, explica a redução da digestibilidade observada nas dietas fornecidas aos suínos submetidos a temperaturas ambientais de $31^{\circ} \mathrm{C}$ no presente estudo.

A suplementação de fitase na dieta influenciou $(\mathrm{P}<0,01)$ na porcentagem de fósforo e de cálcio excretado nas fezes e os resultados foram melhores ajustados pelo modelo linear response plateau, indicando a redução da excreção desses nutrientes até o nível de $300 \mathrm{UF} \mathrm{kg}^{-1}$ de ração, nível a partir do qual a excreção percentual dos nutrientes manteve-se constante no platô, segundo as equações $\mathrm{Y}=15,10167-0,0268 \mathrm{x}, \mathrm{R}^{2}=94,0 \mathrm{e} \mathrm{Y}=5,61108-0,00656 \mathrm{x}, \mathrm{R}^{2}=88,4$, respectivamente, para a excreção de fósforo e cálcio.

Esse resultado é semelhante aos obtidos por FIGUEIRÊDO et al. (2000) que, avaliando dietas formuladas com farelo de arroz integral, para suínos em crescimento, contendo dois níveis de fósforo total $(0,34$

Tabela 2 - Excreção de nutrientes de suínos em crescimento alimentados com dietas suplementadas com fitase sob diferentes ambientes térmicos.

\begin{tabular}{|c|c|c|c|c|c|c|c|c|c|c|}
\hline \multirow{2}{*}{ Variáveis } & \multirow{2}{*}{ Ambiente } & \multicolumn{4}{|c|}{----------Fitase (UF kg ${ }^{-1}$ de ração) ---------- } & \multirow{2}{*}{ Média } & \multicolumn{3}{|c|}{-------------<P------------- } & \multirow{2}{*}{ CV (\%) } \\
\hline & & 0 & 300 & 600 & 900 & & A & $\mathrm{F}$ & $\mathrm{A} * \mathrm{~F}$ & \\
\hline \multirow{3}{*}{ PB excretada, \% } & $23^{\circ} \mathrm{C}$ & 17,05 & 15,99 & 13,04 & 12,11 & $14,77^{\mathrm{b}}$ & 0,07 & 0,26 & 0,84 & 22,42 \\
\hline & $31^{\circ} \mathrm{C}$ & 20,30 & 16,56 & 16,43 & 17,36 & $17,89^{\mathrm{a}}$ & & & & \\
\hline & Média & 18,68 & 16,28 & 14,74 & 14,74 & & & & & \\
\hline \multirow{3}{*}{ P excretado, $\% *$} & $23^{\circ} \mathrm{C}$ & 13,84 & 4,92 & 4,21 & 3,50 & $6,62^{\mathrm{b}}$ & 0,01 & 0,01 & 0,78 & 25,94 \\
\hline & $31^{\circ} \mathrm{C}$ & 17,33 & 9,74 & 10,53 & 8,51 & $11,53^{\mathrm{a}}$ & & & & \\
\hline & Média & 15,59 & 7,33 & 7,37 & 6,00 & & & & & \\
\hline \multirow{3}{*}{ Ca excretado, \%* } & $23^{\circ} \mathrm{C}$ & 4,85 & 1,66 & 2,51 & 1,79 & $2,70^{\mathrm{b}}$ & 0,01 & 0,02 & 0,77 & 33,65 \\
\hline & $31^{\circ} \mathrm{C}$ & 6,76 & 5,28 & 5,33 & 4,68 & $5,51^{\mathrm{a}}$ & & & & \\
\hline & Média & 5,81 & 3,47 & 3,92 & 3,24 & & & & & \\
\hline \multirow{3}{*}{ Zn excretado, $\%$} & $23^{\circ} \mathrm{C}$ & 17,63 & 13,95 & 15,03 & 12,03 & $14,66^{\mathrm{b}}$ & 0,03 & 0,25 & 0,53 & 17,63 \\
\hline & $31^{\circ} \mathrm{C}$ & 18,14 & 16,23 & 17,67 & 17,46 & $17,38^{\mathrm{a}}$ & & & & \\
\hline & Média & 17,89 & 15,09 & 16,35 & 14,75 & & & & & \\
\hline \multirow{3}{*}{ Fe excretado, $\%$} & $23^{\circ} \mathrm{C}$ & 18,17 & 16,24 & 23,51 & 12,14 & 17,52 & 0,73 & 0,76 & 0,55 & 31,16 \\
\hline & $31^{\circ} \mathrm{C}$ & 31,70 & 21,33 & 20,88 & 20,35 & 23,57 & & & & \\
\hline & Média & 24,94 & 18,79 & 22,20 & 16,25 & & & & & \\
\hline \multirow{3}{*}{ Mg excretado, $\%$} & $23^{\circ} \mathrm{C}$ & 16,07 & 10,94 & 16,21 & 15,21 & $12,40^{\mathrm{b}}$ & 0,03 & 0,13 & 0,65 & 23,00 \\
\hline & $31^{\circ} \mathrm{C}$ & 17,62 & 13,82 & 12,42 & 9,68 & $15,72^{\mathrm{a}}$ & & & & \\
\hline & Média & 16,85 & 14,32 & 12,67 & 12,45 & & & & & \\
\hline
\end{tabular}

PB (proteína bruta); P (fósforo); Ca (cálcio); Zn (zinco); Fe (ferro); Mg (magnésio).

Médias na coluna seguidas por letras distintas entre linhas diferem, em nível de $5 \%$ de significância, pelo teste $\mathrm{F}$.

* Efeito linear response plateau $(\mathrm{P}<0,01)$. 
e $0,56 \%$ ), observaram que a suplementação de fitase (1.250UF $\mathrm{kg}^{-1}$ de ração) reduziu em $44,7 \%$ o teor de fósforo excretado nas fezes, melhorando a disponibilidade do nutriente. Da mesma forma, MOREIRA et al. (2003) observaram aumento da digestibilidade do fósforo com o aumento do nível de fitase até $931 \mathrm{UF} \mathrm{kg}^{-1}$ de ração.

A suplementação de fitase nas dietas não influenciou $(\mathrm{P}>0,10)$ na excreção de proteína, zinco, ferro e magnésio nas fezes. A fitase atua sobre os grupos fosfóricos das moléculas de fitato, podendo liberar fósforo e outros nutrientes (CROMWELL et al.,
1995), porém tem-se constatado que a principal ação da enzima é sobre a liberação do fósforo, ao passo que a ação sobre os demais minerais é dependente do tipo de fitato em função dos diferentes cereais (ADEOLA \& SANDS, 2003).

Não houve interação $(\mathrm{P}>0,10)$ entre os níveis de fitase e o ambiente térmico sobre os valores de ED e EM e sobre os coeficientes de digestibilidade da energia e dos nutrientes avaliados (Tabela 3). Dietas fornecidas a suínos submetidos à termoneutralidade apresentaram maiores coeficientes de digestibilidade da proteína ( $P<0,09)$, do fósforo $(\mathrm{P}<0,01)$, do cálcio $(\mathrm{P}<0,02)$, do

Tabela 3 - Coeficiente de digestibilidade dos nutrientes para suínos em crescimento em dietas suplementadas com fitase sob diferentes ambientes térmicos

\begin{tabular}{|c|c|c|c|c|c|c|c|c|c|c|}
\hline \multirow{2}{*}{ Variáveis } & \multirow{2}{*}{ Ambiente } & \multicolumn{4}{|c|}{ 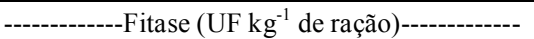 } & \multirow{2}{*}{ Média } & \multicolumn{3}{|c|}{----------------<>P---------------- } & \multirow{2}{*}{$\mathrm{CV}(\%)$} \\
\hline & & 0 & 300 & 600 & 900 & & A & $\mathrm{F}$ & $\mathrm{A}^{*} \mathrm{~F}$ & \\
\hline \multirow{3}{*}{$\mathrm{ED}, \mathrm{kcal} \mathrm{kg}{ }^{-1}$} & $23^{\circ} \mathrm{C}$ & 3.332 & 3.330 & 3.274 & 3.321 & 3.314 & 0,87 & 0,88 & 0,99 & 3,14 \\
\hline & $31^{\circ} \mathrm{C}$ & 3.307 & 3.312 & 3.288 & 3.321 & 3.307 & & & & \\
\hline & Média & 3.320 & 3.321 & 3.281 & 3.321 & & & & & \\
\hline \multirow{3}{*}{ EM, kcal kg ${ }^{-1}$} & $23^{\circ} \mathrm{C}$ & 3.281 & 3.271 & 3.219 & 3.267 & 3.260 & 0,94 & 0,68 & 0,95 & 3,04 \\
\hline & $31^{\circ} \mathrm{C}$ & 3.239 & 3.228 & 3.239 & 3.253 & 3.242 & & & & \\
\hline & Média & 3.260 & 3.254 & 3.229 & 3.260 & & & & & \\
\hline \multirow{3}{*}{$\mathrm{CDaPB}, \%$} & $23^{\circ} \mathrm{C}$ & 82,95 & 84,01 & 86,95 & 83,64 & $84,38^{\mathrm{a}}$ & 0,09 & 0,71 & 0,78 & 5,77 \\
\hline & $31^{\circ} \mathrm{C}$ & 79,70 & 83,44 & 80,64 & 79,66 & $80,86^{\mathrm{b}}$ & & & & \\
\hline & Média & 81,32 & 83,72 & 83,79 & 81,65 & & & & & \\
\hline \multirow{3}{*}{$\mathrm{CDaP}, \% *$} & $23^{\circ} \mathrm{C}$ & 86,16 & 95,08 & 95,78 & 96,50 & $93,38^{\mathrm{a}}$ & 0,01 & 0,01 & 0,78 & 2,59 \\
\hline & $31^{\circ} \mathrm{C}$ & 82,67 & 90,26 & 89,46 & 91,47 & $88,47^{\mathrm{b}}$ & & & & \\
\hline & Média & 84,41 & 92,67 & 92,62 & 93,99 & & & & & \\
\hline \multirow{3}{*}{$\mathrm{CDaCa}, \% *$} & $23^{\circ} \mathrm{C}$ & 95,15 & 98,34 & 97,49 & 98,20 & $97,27^{\mathrm{a}}$ & 0,02 & 0,01 & 0,77 & 1,44 \\
\hline & $31^{\circ} \mathrm{C}$ & 93,23 & 94,72 & 94,67 & 95,32 & $94,48^{\mathrm{b}}$ & & & & \\
\hline & Média & 94,19 & 96,53 & 96,08 & 96,76 & & & & & \\
\hline \multirow{3}{*}{$\mathrm{CDaZn}, \%$} & $23^{\circ} \mathrm{C}$ & 82,37 & 86,05 & 84,97 & 87,97 & $85,34^{\mathrm{a}}$ & 0,03 & 0,25 & 0,52 & 3,36 \\
\hline & $31^{\circ} \mathrm{C}$ & 81,85 & 83,76 & 82,32 & 82,54 & $82,62^{\mathrm{b}}$ & & & & \\
\hline & Média & 82,11 & 84,91 & 83,65 & 85,25 & & & & & \\
\hline \multirow{3}{*}{$\mathrm{CDaFe}, \%$} & $23^{\circ} \mathrm{C}$ & 85,01 & 84,47 & 76,49 & 87,86 & $83,57^{\mathrm{a}}$ & 0,09 & 0,14 & 0,24 & 4,54 \\
\hline & $31^{\circ} \mathrm{C}$ & 81,83 & 81,29 & 79,12 & 79,65 & $80,47^{\mathrm{b}}$ & & & & \\
\hline & Média & 83,42 & 82,88 & 77,81 & 83,76 & & & & & \\
\hline \multirow{3}{*}{ CDaMg, \%* } & $23^{\circ} \mathrm{C}$ & 83,93 & 89,39 & 88,95 & 90,32 & $88,08^{\mathrm{a}}$ & 0,02 & 0,06 & 0,95 & 3,64 \\
\hline & $31^{\circ} \mathrm{C}$ & 82,38 & 86,18 & 83,79 & 85,51 & $84,37^{\mathrm{b}}$ & & & & \\
\hline & Média & 83,16 & 87,79 & 86,37 & 87,92 & & & & & \\
\hline
\end{tabular}

ED (energia digestível); EM (energia metabolizável); CDaPB (coeficiente de digestibilidade aparente da proteína bruta); CDaP (coeficiente de digestibilidade aparente do fósforo); $\mathrm{CDaCa}$ (coeficiente de digestibilidade aparente do cálcio); CDaZn (coeficiente de digestibilidade aparente do zinco); $\mathrm{CDaFe}$ (coeficiente de digestibilidade aparente do ferro); CDMg (coeficiente de digestibilidade aparente do magnésio). Médias na coluna seguidas por letras distintas entre linhas diferem, ao nível de $10 \%$ de probabilidade, pelo teste $\mathrm{F}$.

* Efeito linear response plateau $(\mathrm{P}<0,01)$. 
zinco $(\mathrm{P}<0,03)$, do ferro $(\mathrm{P}<0,09)$ e do magnésio $(\mathrm{P}<0,02)$. Contudo, os valores de ED e EM das dietas experimentais não foram afetados $(\mathrm{P}>0,10)$ pelos ambientes térmicos.

Como consequência da menor excreção nas fezes, a suplementação de fitase também influenciou $(\mathrm{P}<0,01)$ nos coeficientes de digestibilidade do fósforo e cálcio, assim como do magnésio, e o modelo linear response plateau foi o que melhor ajustou as respostas para estes parâmetros, indicando aumento do coeficiente de digestibilidade destes nutrientes até o nível de 300UF $\mathrm{kg}^{-1}$ de ração, nível a partir do qual os coeficientes mantiveram-se constantes no platô, conforme as equações: $Y=84,89833+0,02680 x, R^{2}=92,7$; $\mathrm{Y}=94,38892+0,00656 \mathrm{x}, \mathrm{R}^{2}=95,9 \mathrm{e} \mathrm{Y}=83,68817+0,01059 \mathrm{x}$, $\mathrm{R}^{2}=86,0$, respectivamente, para o fósforo, cálcio e magnésio.

A partir dos resultados obtidos no presente estudo, pode-se constatar aumento de 8,9\% na digestibilidade do fósforo com a suplementação de $300 \mathrm{UF} \mathrm{kg}^{-1}$ de ração em relação à dieta não suplementada. Aumentos do coeficiente de digestibilidade do fósforo a partir da suplementação de fitase também foram constatados por outros pesquisadores, porém com valores superiores ao observado no presente estudo. Conforme KETAREN et al. (1993), a suplementação de 1.000UF kg-1 aumentou em 53,0\% a digestibilidade do fósforo aparente do farelo de soja para suínos em crescimento e terminação. Também FIGUEIRÊDO et al. (2000) constataram aumento de $40,8 \%$ da digestibilidade do fósforo do farelo de arroz integral com a suplementação de 1.250UF $\mathrm{kg}^{-1}$ de ração.

Ao se avaliar a digestibilidade de cálcio no presente estudo, pode-se inferir que a fitase na concentração de $300 \mathrm{UF} \mathrm{kg}^{-1}$ de ração aumentou em 2,4\% seu coeficiente de digestibilidade em relação à dieta não suplementada. MACHINSKY et al. (2010), em pesquisa com suínos em crescimento e dietas contendo dois níveis de cálcio $(0,5$ ou $0,72 \%)$, suplementadas ou não com 500UF de fitase $\mathrm{kg}^{-1} \mathrm{de}$ ração, verificaram que a digestibilidade de cálcio também aumentou significativamente em dietas contendo fitase.

A suplementação de fitase não influenciou $(\mathrm{P}>0,10)$ nos valores de ED e EM das dietas, bem como nos coeficientes de digestibilidade da proteína, zinco e ferro. Em geral, os resultados relacionados aos efeitos da fitase sobre a digestibilidade do nitrogênio e aminoácidos das dietas têm sido inconsistentes (ADEOLA \& SANDS, 2003) e, em várias pesquisas, a suplementação de fitase não melhorou a digestibilidade ileal dos aminoácidos (TRAYLOR et al., 2001), nem a digestibilidade da fração proteica da dieta
(MACHINSKY et al., 2010), de forma similar à resposta observada no presente estudo.

\section{CONCLUSÃO}

Dietas fornecidas para suínos submetidos a temperaturas ambientais elevadas $\left(31^{\circ} \mathrm{C}\right)$ apresentam piores coeficientes de digestibilidade da proteína, fósforo, cálcio, zinco, ferro e magnésio e, portanto, apresentam maior excreção percentual desses nutrientes nas fezes, quando comparados aos suínos submetidos à termoneutralidade. A suplementação de fitase não altera o valor energético da dieta e o coeficiente de digestibilidade da proteína bruta, mas aumenta o coeficiente de digestibilidade de fósforo, cálcio e magnésio da dieta e reduz a excreção percentual de fósforo e cálcio nas fezes dos suínos. O nível de inclusão recomendado é de $300 \mathrm{UF} \mathrm{kg}^{-1}$ de ração, independentemente da condição térmica ambiental.

\section{AGRADECIMENTO}

Os autores agradecem à Fundação de Apoio ao Desenvolvimento do Ensino, Ciência e Tecnologia do Estado de Mato Grosso do Sul (FUNDECT), pelo financiamento deste estudo.

\section{COMITÊ DE ÉTICA E BIOSSEGURANÇA}

Protocolo comitê de ética nº 315/2011.

\section{REFERÊNCIAS}

ADEOLA, O.; SANDS, J.S. Does supplemental dietary microbial phytase improve amino acid utilization? A perspective that it does not. Journal of Animal Science, v.81, E78-E85, 2003. Disponível em: <http://jas.fass.org/content/81/14_suppl_2/ E78.full.pdf + html>. Acesso em: 10 mar. 2011.

AOAC (Association of Official Analitical Chemists). Official methods of analysis. 14.ed. Arlington, 1984. 1141p.

CROMWELL, G.L. et al. Efficacy of low-activity, microbial phytase in improving the bioavailability of phosphorus in cornsoybean meal diets for pigs. Journal of Animal Science, v.73, p.449-456, 1995. Disponível em: <http://jas.fass.org/ content/73/2/449.full.pdf + html $>$. Acesso em: 05 mar. 2011.

FIGUEIRÊDO, A.V. et al. Ação da fitase sobre a disponibilidade biológica do fósforo, por intermédio da técnica de diluição isotópica, em dietas com farelo de arroz integral para suínos. Revista Brasileira de Zootecnia, v.29, p.177-182, 2000. Disponível em: $<$ http://www.scielo.br/scielo.php?script=sci_arttext\&pid=S151635982000000100024>. Acesso em: 10 abr. 2011. doi: 10.1590/ S1516-35982000000100024.

GUERNSEY, D.L.; STEVENS, E.D. The cell membrane sodium pump as a mechanism for increasing thermogenesis during cold acclimation in rats. Science, v.196, p.908-909, 1977. Disponível em: <http://www.sciencemag.org/content/196/4292/ 
908.full.pdf $>$. Acesso em: 10 mar. 2011. doi: 10.1126/ science. 860125 .

HUYNH, T.T.T. et al. Effects of increasing temperatures on physiological changes in pigs at different relative humidities. Journal of Animal Science, v.83, p.1385-1396, 2005 Disponível em: <http://www.animal-science.org/content/83/6/ 1385.full.pdf + html $>$. Acesso em: 25 nov. 2011

JENDZA, J.A. et al. Escherichia coli phytase improves growth performance of starter, grower, and finisher pigs fed phosphorusdeficient diets. Journal of Animal Science, v.83, p.18821889, 2005. Disponível em: <http://www.animal-science.org/ content/83/8/1882.full.pdf + html>. Acesso em: 10 ago. 2011.

KETAREN, P.P. et al. Phosphorus studies in pig. 3. Effect of phytase supplementation on the digestibility and availability of phosphorus in soybean meal for grower pigs. British Journal of Nutrition, v.70, p.289-311, 1993. Disponível em: <http://journals.cambridge.org/ download.php?file =\%2 FBJN\%2FBJN $70 \quad 01 \% 2$ F S 00 07114593001242a.pdf\&code $=$ b7194c3e0d9b575850aadfcbedad50cd $>$. Acesso em: 15 mar. 2011. doi: 10.1079/BJN19930123.

KIEFER, C. et al. Resposta de suínos em crescimento mantidos em diferentes temperaturas. Archivos de Zootecnia, v.58, p.55-64, 2009. Disponível em: < http://scielo.isciii.es/pdf/azoo/ v58n221/art6.pdf>. Acesso em: 15 mar. 2011. doi: 10.4321/ S0004-05922009000100006.

KOONG, L.J. et al. Effects of plane of nutrition on organ size and fasting heat production in pigs. Journal of Nutrition, v.112, p.1638-1642, 1982. Disponível em: <http://jn.nutrition.org/ content/112/8/1638.long >. Acesso em: 15 mar. 2011.

MACHINSKY, T.G. et al. Digestibilidade de nutrientes e balanço de $\mathrm{Ca}$ e $\mathrm{P}$ em suínos recebendo dietas com ácido butírico, fitase e diferentes níveis de cálcio. Ciência Rural, v.40, p.2350-2355, 2010. Disponível em: $<\mathrm{http} / /$ www.scielo.br/scielo.php?pid=S0103$84782010001100016 \&$ script $=\mathrm{sci}$ arttext $>$. Acesso em: $15 \mathrm{abr}$ 2011. doi: http://dx.doi.org/10.1590/S0103-84782010001100016.

MOREIRA, J.A. et al. Biodisponibilidade e perdas endógenas mínimas de $\mathrm{P}$ em dietas com níveis crescentes de fitase para suínos em crescimentos pela técnica de diluição isotópica. Arquivo Brasileiro de Medicina Veterinária e Zootecnia, v.55, p.350-356, 2003. Disponível em: <http://www.scielo.br/scielo.php?pid=S010209352003000300016\&script=sci_arttext $>$. Acesso em: 15 mar. 2011. doi: http://dx.doi.org/10.1590/S0102-09352003000300016.

OLIVEIRA, R.F.M.; DONZELE, J.L. Effect of environmental temperature on performance and on physiological and hormonal parameters of gilts fed at different levels of digestible energy. Animal Feed Science and Technology, v.81, p.319-331, 1999. Disponível em: < http://directory.umm.ac.id/Data\%20Elmu/jurnal/ A/Animal\%20Feed\%20Science\%20and\%20Technology/ Vol81.Issue3-4.Oct1999/10391.pdf>. Acesso em: 15 abr. 2011.

PERDOMO, C.C. Conforto ambiental e produtividade de suínos. In: SIMPÓSIO LATINO - AMERICANO DE NUTRIÇÃO DE SUÍNOS, 1994, São Paulo, SP. Anais... São Paulo: CBNA, 1994. p.19-26.

ROSTAGNO, H.S. et al. Composição de alimentos e exigências nutricionais. Tabelas brasileiras para aves e suínos. 2.ed. Viçosa, MG: UFV, 2005. 186p.

SAKOMURA, N.; ROSTAGNO, H.S. Métodos de pesquisa em nutrição de monogástricos. Jaboticabal, SP: FUNEP, 2007. 283p.

SAMPAIO, C.A.P. et al. Avaliação do ambiente térmico em instalações para crescimento e terminação de suínos utilizando os índices de conforto térmico nas condições tropicais. Ciência Rural, v.34, p.785-790, 2004. Disponível em: <http://www.scielo.br/pdf/ cr/v34n3/a20v34n3.pdf>. Acesso em: 15 abr. 2011. doi: http:// dx.doi.org/10.1590/S0103-84782004000300020.

SILVA, D.J.; QUEIROZ, A.C. Análise de alimentos. Métodos químicos e biológicos. 3.ed. Viçosa: Universidade Federal de Viçosa, 2002. 235p.

TRAYLOR, S.L. et al. Effects of level of supplemental phytase on ileal digestibility of amino acids, calcium and phosphorus in dehulled soybean meal for growing pigs. Journal of Animal Science, v.79, p.2634-2642, 2001. Disponível em: <http:// jas.fass.org/content/79/10/2634.full.pdf + html $>$. Acesso em: 15 abr. 2011. 